\title{
A STUDY OF ACTIVATED SLUDGE DEWATERING IN EXPERIMENTAL REED-PLANTED OR UNPLANTED SLUDGE DRYING BEDS
}

\author{
A.Liénard*, Ph.Duchène ${ }^{* *}$, D.Gorini* \\ *CEMAGREF, Division Qualité des Eaux \\ 3bis, Quai Chauveau, 69336 - LYON Cedex 09 - FRANCE \\ **CEMAGREF, Division Qualité des Eaux \\ 14, Avenue de Saint Mandé, 75012 - PARIS - FRANCE
}

\begin{abstract}
The study was carried out, from June 89 to December 1992, on 3 experimental concrete beds of $20 \mathrm{~m}^{2}$ each, constructed close to an extended aeration plant. Beds 1 and 2 were planted with reeds, bed 3 was considered as an unplanted control bed. During the first phase (June 89-May 90), most of the reeds in bed 2 died in spite of the influent sludge dose of $70 \mathrm{~g}$. of SS.m ${ }^{-2} \cdot \mathrm{d}^{-1}$. During the second phase (917 days) the 3 beds were aerated from the bottom and fed with sludge, directly extracted from the oxidation ditch (Dry Matter content $0.3 \%$ ). The influent sludge load varied between 120 and $160 \mathrm{~g}$ of SS.m-2. $\mathrm{d}^{-1}$ after the second growth season (with peak values of up to $215 \mathrm{~g}$ of SS.m-2. $\mathrm{d}^{-1}$ in the summer of 1991). Bed 3 didn't clog, and the major contribution of the reeds to maintaining a high and regular liquid conductivity in the sludge has been proven, allowing easier and higher dosing of the planted beds. Monitoring of the percolation flow emphasised a high mineralisation process in the rhizosphere. The accumulated sludge (Dr Matter content $\approx 11 \%$ ) can be dug out together with the reeds using a mechanical digger and sprea: fields with a solid manure spreader. A regrowth of reeds occurs directly from rhizomes remaining in the drainage layer and in a few centimetres of sludge at the bottom of the bed.
\end{abstract}

\section{KEYWORDS}

Activated sludge; case study; reeds; sludge dewatering; sludge drying beds; small wastewater treatment plants.

\section{INTRODUCTION}

When these tests started in 1989, the CEMAGREF had been interested for several years in the treatment of wastewater using biological processes fixed on fine media planted with various species of aquatic plants (Liénard et al., 1990a). Among the various plant species used in the process developed by Dr. SEIDEL in Germany (Boutin, 1987), the reed (Phragmites communis), planted in drained, alternately fed beds, seemed to have interesting possibilities for the treatment of raw wastewater, loaded with suspended solids (SS).

It was of interest to confirm this aptitude for dewatering sludge from extended aeration plants, a medium that is notorious for clogging, since this allows higher SS doses to be loaded to cause rapid accumulation of deposits. This line of thought corresponded with a request by the SAUR (the Société d'Aménagement Urbain et Rural, who ordered the study) who run a large number of $<5000$ p.e., extended aeration plants. The main findings of the bibliographical research carried out whilst the experimental site was being set up have already been published (Liénard et al. 1990b). 
These included a detailed description of the beds and ancillary equipment as well as the initial results obtained in 1989 in Bourg Argental. When the reeds died in bed 2 (non aerated drainage layer) at the end of the 1989-1990 winter (Liénard et al. 1990b), the corresponding drying rates were low (around $3 \mathrm{~mm} . \mathrm{h}^{-1}$ ) and of the same order as in the unplanted bed $3\left(2.5 \mathrm{~mm} \cdot \mathrm{h}^{-1}\right)$.

As opposed to this, in bed 1 (aerated drainage layer, made up of Bioterra ${ }^{\circledR}$ blocks), the reeds had survived and the average drying rate was significantly higher $\left(6 \mathrm{~mm} \cdot \mathrm{h}^{-1}\right)$. Comparing these observations, it appeared that maximum reed growth is a guarantee of effective dewatering, and therefore essential to favour by all means compatible with the need for the process to be rustic. Therefore, in April-May 1990 the experimental site was modified and a new test phase was started in June 1990. Only the characteristics and results of the latter are presented in this article.

\section{EQUIPMENT AND METHODS}

\section{The experimental beds}

The modified drainage layer of beds 2 and 3. The main modification was the replacement of the 30/60 $\mathrm{mm}$ stones by hollow concrete bricks that are in contact with the atmosphere via 4 × $200 \mathrm{~mm}$ PVC tubes placed in the corners of the bed, as for the Bioterra ${ }^{\circledR}$ blocks in bed 1 , as early as June 1989 . Hollow concrete bricks (an everyday building material) were chosen due to the fact that they have large cavities that favour air circulation, at a cost that is significantly lower than Bioterra ${ }^{\circledR}$ blocks. The intermediary layers of aggregate (Liénard et al., 1990b) were reused, but the soil used for the planting layer, also used on bed 3, was mixed in equal proportions with sand.

Planting. Only bed 2 was planted with seedlings, grown in little earth-filled plastic pots and bought from a specialised nursery. Scarcely 1 month after planting the reeds on bed 2, it was decided to stop watering with treated water and to feed beds 2 and 3 with sludge. On bed 3, still considered as an unplanted control bed, various plants grew spontaneously (mostly Echinochloa crus galli) which were not removed. As far as possible, it was fed and managed under the same conditions as bed 2. However, the management procedure did not correspond with that of a conventional sludge drying bed in France in which the dried sludge is systematically taken out before raw sludge is put in again.

\section{Bed feeds}

The beds were fed by a pump, placed directly in the oxidation ditch. The pump start-up was programmed and activated at least 20 minutes after the aeration turbine had operated in order to ensure that the sludge was uniform in the ditch. The bed feeds were progressively individualised and automated, using programmed timers and solenoid valves, installed by the SAUR. However, the beds could be manually fed in the winter months (especially during December and January) when temperatures stabilise for several consecutive days at negative values.

\section{Experimental procedure}

Regular on-site monitoring. On each visit (approximately every 14 days), manual observations were recorded on a field record book. This involves taking readings from the various counters on the solenoid valves and on the feed and the percolation flow discharge pumps, recording the sludge levels in the beds, the maximum and minimum air temperatures and the rainfall gauge level. Sludge samples are taken to regularly determine the SVI (Sludge Volume Index), the TSS (Total Suspended Solids) and VSS (Volatile Suspended Solids) contents and occasionally the NK-N (Kjeldahl Nitrogen), the PT-P (Total Phosphorous) and $\mathrm{HCO}_{3}^{-}$(bicarbonate) contents.

During 1991, the equipment was upgraded with electronic sensors and data recorders enabling automatic processing of meteorological data (the temperature in each of the beds and of ambient air, solar-meter, rain meter) and electrochemical measurements that were performed on a sporadic basis (the redox potential and conductivity in the percolation flows). 
Operating times of the feed pump and of the solenoid valves and small pumps located in an inspection hole opposite each of the beds to discharge the percolation flows, were also electronically recorded and loaded down onto a lap-top computer.

Percolation flow quality monitoring periods. Relays allowing control of automatic samplers according to the number of start-ups of the percolation flow discharge pumps were also used from October 1991. The samples taken are therefore proportional to the flow rates and allow flux calculation as a function of drying rates.

There were 3 monitoring periods using this equipment on beds 2 and 3 (in October 1991, April 1992 and May 1992). On bed 1, the monitoring periods of October 1991 and September 1992 were completed by a final monitoring period in December 1992, following a percolation flow recycling test that lasted 2 months between mid-October and December the 14th 1992. This test was performed to determine the system's hydraulic capacities, by sprinkling it with low SS-loaded water. The device worked for 2 times three hours a day on Mondays, Tuesdays, Fridays, Saturdays and Sundays. Wednesday, on one week in two, was the day designated for influent sludge feeds, in 7 sequences of 16 minutes each, and Thursday was reserved for drying.

Determination of the influent sludge loads. In order to minimise the risk of errors inherent in the possibility of blocked valves or ducts, the predetermined sludge loads are post-evaluated, taking account of the extracted volumes, according to the following formula :

$$
\mathrm{S}=\{(\mathrm{T} \times \mathrm{Q})-((\mathrm{R}+\Delta \text { sludge }) \times \mathrm{A})\} \times \mathrm{C} \quad \text { with }
$$

$S=$ quantity of influent sludge load between 2 visits (in $\mathrm{g}$ );

$\mathrm{T}=$ the operating time of the hydraulic pumps between 2 visits (in sec.);

$\mathrm{Q}=$ unit flow rate of the hydraulic pumps (in litres.sec ${ }^{-1}$ );

$\mathrm{R}=$ the height of rainfall between 2 visits (in $\mathrm{mm}$ );

$\Delta$ sludge $=$ the difference between the thickened sludge levels on each visit, positive or negative values (in $\mathrm{cm} / 10$ ).

$A=$ the surface area of each bed $\left(20 \mathrm{~m}^{2}\right)$;

$\mathrm{C}=$ the moving average of the TSS concentrations in the oxidation ditch on 2 successive visits (in g. $\mathrm{l}^{-1}$ ).

No account is taken of evaporation-sweating and the loads determined in this way can be considered as minimum loads. This is not a problem since a real-size installation has to be designed on the basis of performance levels in the winter-time, the most unfavourable season during which evaporation-sweating is negligible.

Increases in thickened sludge residue heights. The level of the thickened sludge in each of the beds is read on graduated scales. These values are subject to errors due to : a) bed surface irregularities, b) irregular intervals between visits and influent feed sequences, and c) the weather conditions at the time of taking the measurements. For this reason the change in sludge height can only be validly analysed over quite long periods (of around 4 to 5 months) with trends being determined by adjusting the calculations using the cumulative influent sludge flows and the change in the stock height. The heights are expressed in centimetres for $100 \mathrm{~kg}$ of TSS.m-2

Tested feed cycles. 3 cycles were investigated over long periods :

- daily feed to bed 1 Between June 1990 and April 1991, before first being desludged in 1991 as well as beds 2 and 3 during the first year of growth (up to June 1991) ;

- a 14 day cycle ( 1 or 2 days of feed comprising 3 or 4 sequences of influent flow per day and 12 or 13 rest days) on bed 1 after desludging in July 1991, up to December 1992. On beds 2 and 3, this cycle was studied between July and November 1991 ;

- a 28 day cycle ( 3 to 7 days of feed, then rest for 21 to 25 days) on beds 2 and 3 between November 1991 and December 1992.

Desludging the beds. Besides the desludging operation that was necessary to reconstruct the drainage layer in beds 2 and 3 in May 1990, desludging was carried out on two other occasions, this being what should correspond with a normal routine operational procedure on such an installation. 
The first involved bed 1 in July 1991 after its feed had been stopped for 70 days. The second was carried out on all 3 beds, in December 1992 at the end of testing.

A mechanical digger, with a double bucket, cuts and pulls away the parts of the reeds that are above and below the ground, at the same time as the thickened sludge. All this is put in a solid muck spreader and spread on neighbouring fields. A residual layer of sludge, containing numerous rhizomes and roots, is left at the bottom of the bed ensuring spontaneous reed regrowth.

During desludging, sludge samples were taken, from visually different parts of the sludge. These enabled the dry matter content to be estimated as well as that of organic matter and sludge stock nutrients and thus enabled a materials balance to be carried out of influent and extracted sludge.

\section{Average weather conditions}

The minimum and maximum temperatures varied between $-11^{\circ} \mathrm{C}$ in January 1992 and $45^{\circ} \mathrm{C}$ in July 1990 . The average rainfall was 890 mm.year ${ }^{-1}$ with daily rainfall exceptionally reaching $40 \mathrm{~mm}^{-d_{a y}{ }^{-1}}$. The solar energy measured on the site varied in magnitude from $30 \mathrm{Wh} . \mathrm{m}^{-2}$ (when there was no sun and when the beds were not in direct sunlight, in December and January) and 950 Wh.m $\mathrm{m}^{-2}$ in summer.

\section{Influent sludge quality}

The treatment plant is underloaded in terms of organic matter but is hydraulically overloaded due to the infiltration of parasitic run-off water into the sewerage system. This region's sub-soil is crystalline, the water collected by the system and consequently the extended aeration plant's sludge is of low mineral content and slightly acidic.

TABLE 1 AVERAGE VALUES (MIN. - MAX.) FOR A FEW CHARACTERISTIC PARAMETERS OF THE INFLUENT SLUDGE

\begin{tabular}{lc|lc}
\hline pH & $6.5-7.0$ & NK-N $\left(\mathrm{mg} . \mathrm{l}^{-1}\right)$ & $193(75-350)$ \\
Conductivity $\left(\mu \mathrm{S} . \mathrm{cm}^{-1}\right)$ & 250 & PT-P (mg.l $\left.\mathrm{l}^{-1}\right)$ & $46(18-83)$ \\
TSS $\left(\mathrm{g} . \mathrm{l}^{-1}\right)$ & $2.75(1.1-5.0)$ & $\mathrm{HCO}_{3}^{-}\left(\mathrm{mg}^{-1} \mathrm{l}^{-1}\right)$ & $90(60-130)$ \\
TVS (in \%) & $72,5(59.4-80.0)$ & SVI $\left(\mathrm{ml.g}^{-1}\right)$ & $370(150-515)$ \\
\hline
\end{tabular}

The TSS concentration in the aeration plant is mostly very low and microscopic tests reveal a high degree of filamentous bacteria development. This implies mediocre settling capability, which is confirmed by the high Sludge Volume Index (SVI) values.

\section{RESULTS}

\section{Influent sludge dose and the compared increase in residual sludge height}

During the first year after planting or after desludging the beds. An indicative dose of $50 \mathrm{~g}$ of TSS m $\mathrm{m}^{-2} \cdot \mathrm{j}^{-1}$ was predefined for the beds 2 and 3 and adapted according to the visual appearance of the seedlings in bed 2 in order to ensure their correct growth. Since bed 2 had been fed with less sludge it was necessary to reestablish equality as far as possible.

This was done at the end of the summer (arbitrarily designated as the beginning of November, with winter going from November to mid-April) before starting the 2 nd growth season during which the beds could be fed at higher dose rates.

Figure 1 shows that bed 2 is very sensitive in the winter, when the seedlings have only just taken root and their stems are still small : very slightly increasing the dose causes a sharp increase in the sludge level ; as opposed to this, a decrease of around $45 \%$ in the influent dose to the unplanted control bed (3), between the summer and the winter, logically causes a smaller increase in the sludge stock. 
On bed 1, after desludging in July 1991, many roots and rhizomes remained in the drainage layer and the thin layer of sludge that was deliberately left at the bottom of the bed. In the summer new shoots quickly grew (increases of $25 \mathrm{~mm} . \mathrm{d}^{-1}$ were observed) which caused a slower increase in sludge height than in beds 2 and 3, at an almost equivalent dose. Good growth during the summer enabled the liquid influent sludge flow to dry well during the winter, as shown by the arrow direction for a TSS dose of approximately 125 g.m $\mathrm{m}^{-2} \cdot \mathrm{j}^{-1}$.

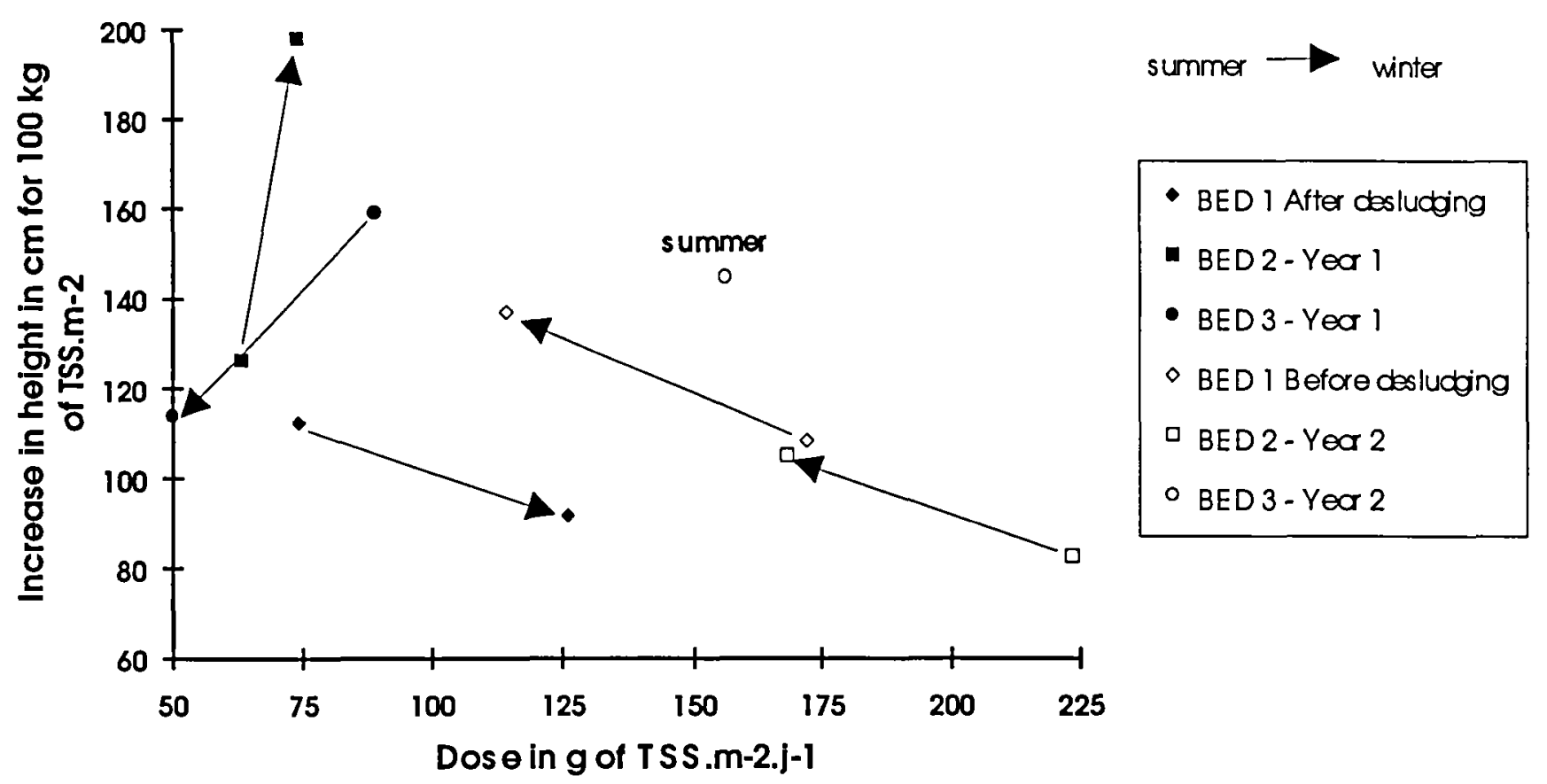

Figure 1 : Variations in residual sludge levels in the 3 experimental beds at different stages in reed development and different seasons.

During the second year of growth or before desludging of bed 1. Figure 1 shows that, even with lower doses, there is a logical deterioration in performance from summer to winter. Whilst this period is unfavourable for all biological systems, the reduced activity of micro-organisms responsible for mineralization processes cannot be the only explanatory factor. For bed 1, the slightly greater increase than that noted after desludging at a virtually identical dose, is certainly related to the fact that at this time the bed was fed daily and that the sludge stock was regularly diluted, thus hindering thickening.

For bed 3, the summer point shows a distinct difference in increase compared with bed 2 in spite of it also receiving a high sludge load. On the latter, plant-growth was sufficiently developed to achieve the expected efficiency. In winter, on bed 3 , the great difference in sludge levels on a restricted number of data sets makes it impossible to determine any significant trend.

In any case adjustments are less valid on bed 3, especially towards the end of the test period. With the free height on the beds being less and the flow of interstitial water being slower, the influent feed had to be split up to a great extent. Consequently, drying was sometimes only partial at the time of taking sludge level readings.

The following trends are determined over long time-periods :

- an increase of $136 \mathrm{~cm}$ for a dose of $141 \mathrm{~g}$ of TSS.m $\mathrm{m}^{-2} \cdot \mathrm{j}^{-1}$, over 311 days on bed 1 ( 1 day cycle), - an increase of $85 \mathrm{~cm}$ for a dose of $107 \mathrm{~g}$ of TSS.m $\mathrm{m}^{-2} \cdot \mathrm{j}^{-1}$, over 463 days on bed 1 (14 day cycle), - an increase of $87 \mathrm{~cm}$ for a dose of $158 \mathrm{~g}$ of TSS.m ${ }^{-2} . \mathrm{j}^{-1}$, over 552 days on bed 2 , in the second season (14 day cycle, then 28 days during the last year),

- an increase of $84 \mathrm{~cm}$ for a dose of $118 \mathrm{~g}$ of TSS.m $\mathrm{m}^{-2} \cdot \mathrm{j}^{-1}$, over 552 days in bed 3, in the second year (14 day cycle, then 28 days during the last year).

In summary, it may be noted that the expected clogging of the unplanted control bed did not occur and that it has a similar increase in the sludge level to bed 2 at an average dose of less than $25 \%$. 
Total influent sludge loads to the beds

Including the first year of reed growth, the experimental period was of 917 days for beds 2 and 3 and 524 days for bed 1. The average influent liquid volume to each of is respectively : 42, 35, and 39 mm.day $^{-1}$. Rainfall is equivalent to $2.5 \mathrm{~mm}$.day ${ }^{-1}$, and therefore does not represent a major factor.

TABLE 2 : QUANTITY OF INFLUENT SLUDGE LOAD TO BED 1 BETWEEN JULY 1991 AND DECEMBER 1992 AND BEDS 2 AND 3 BETWEEN JULY 1990 AND DECEMBER 1992

\begin{tabular}{crcc}
\hline & BED 1 & BED 2 & BED 3 \\
Volume (in m ${ }^{3}$ ) & 412 & 774 & 640 \\
TSS (in kg) & 1121 & 2213 & 1796 \\
VSS (in kg) & 769 & 1581 & 1285 \\
NK-N (in kg) & 75 & 154 & 125 \\
PT-P (in kg) & 18 & 37 & 30 \\
\hline
\end{tabular}

During the two month period in which percolation flow was recycled to bed 1, the latter had an influent liquid volume of approximately $360 \mathrm{~m}^{3}$, representing a water height of $300 \mathrm{~mm}$.day ${ }^{-1}$. The corresponding, average air temperature was determined as $5^{\circ} \mathrm{C}$ (maximum : $11^{\circ} \mathrm{C}$, minimum : $-2^{\circ} \mathrm{C}$ ), whilst in the bed itself, which had a sludge height of $40 \mathrm{~cm}$, a temperature probe immersed into the lower $1 / 3$ recorded the following values : average : $8^{\circ} \mathrm{C}$, maximum : $12^{\circ} \mathrm{C}$ and minimum $: 4^{\circ} \mathrm{C}$.

\section{Drying dynamics}

The reed stems, and their rhizomes and roots in contact with the beds' drainage layer, create a network that enables the interstitial water to be constantly removed, even in winter. The plots shown in figure 2 , determined when the beds were under the same static pressure conditions, highlight the very different behaviours. The minimum temperatures recorded during these operations were around $-8^{\circ} \mathrm{C}$ and the sludge surface was frozen to a depth of several centimetres. Mostly however, there remained a ring around the reed stems that was free of ice which ensured continuity. Only snow, which may flatten the reeds, can jeopardise the persistence of this phenomenon.

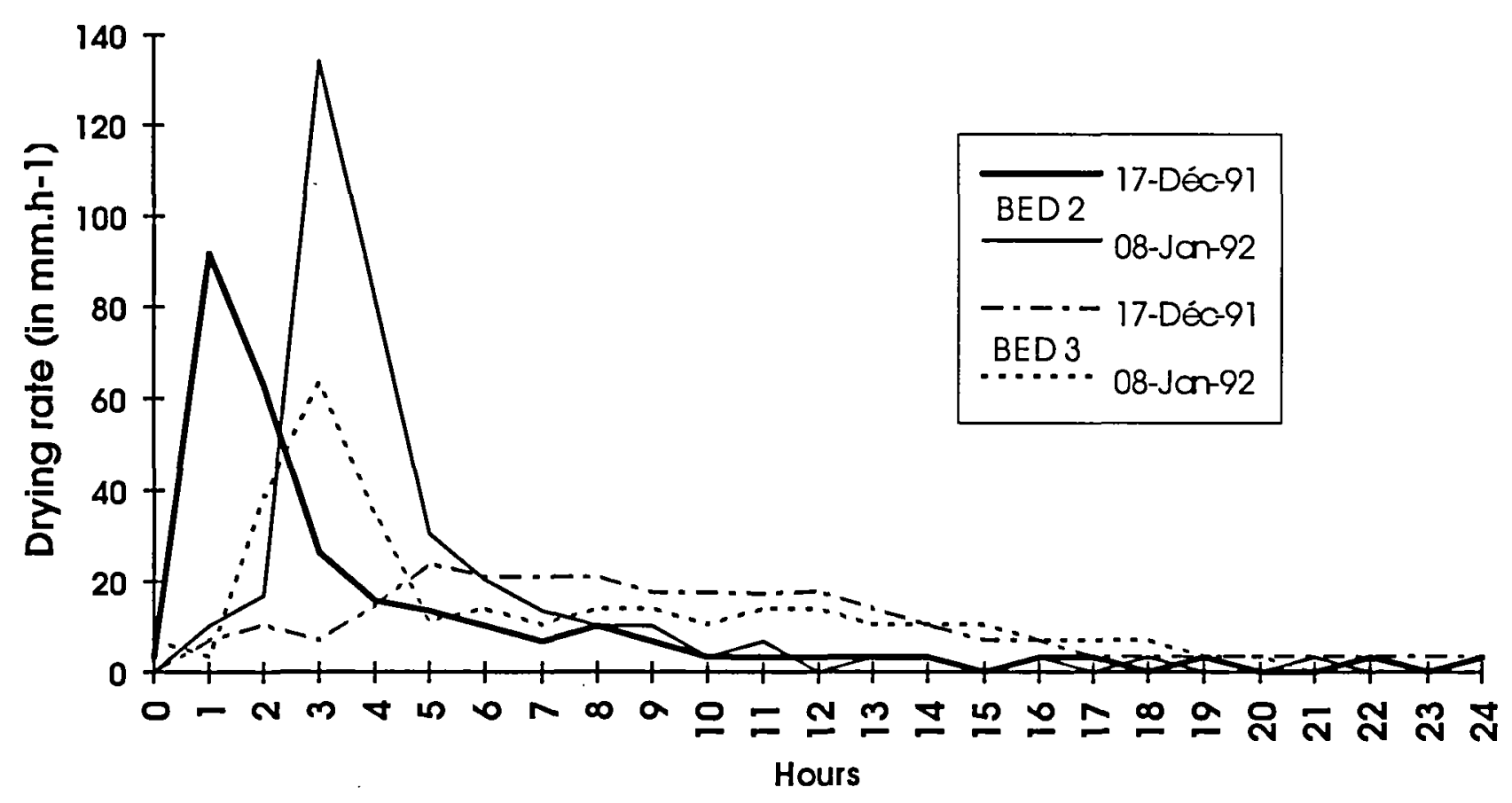

Figure 2 : Comparison in the change in drying rate between a planted bed and an unplanted control bed. 
Bed 3 is covered with a layer of well mineralised sludge, host to an abundance of perennial plants that wither in winter and that float according to the influent sludge flows and drying cycles. This forms an insulating layer over most of the sludge stock which does not ice up at the edges. Drying is a lot slower and occurs later on the unplanted control bed that behaves like a "sludge lagoon" with a porous bottom.

A pre-thickened sludge layer acts as the filter ; from time to time, pockets of water are discharged, sometimes causing sludge dilution. The higher drying rates, seen between October 1991 and May 1992 have considerably decreased from 60 to $15 \mathrm{~mm} \cdot \mathrm{h}^{-1}$, which would tend to favour the hypothesis that drying decreases as a function of the stored thickness of sludge. This phenomenon is not observed on the planted beds, due to the above mentioned connecting network created by the reeds throughout the depth of the sludge.

\section{Percolation flow quality}

The statistics given in table 3 , show lower organic matter contents in the percolation flow of the two planted beds than in that of bed 3. These figures confirm the sporadic sludge losses that were previously mentioned to explain the identical increases in sludge on beds 2 and 3.

\section{TABLE 3 : PERCOLATION FLOW COD AND TSS CONCENTRATIONS FROM OCTOBER 1991 TO DECEMBER 1992}

\begin{tabular}{c|cc|cc|cc}
\hline & \multicolumn{2}{|c|}{ BED 1 } & \multicolumn{2}{c|}{ BED 2 } & \multicolumn{2}{c}{ BED 3 } \\
& COD & TSS & COD & TSS & COD & TSS \\
Average & 43.0 & 19.4 & 85.3 & 34.3 & 102.1 & 103.4 \\
Std. Dev. & 22.20 & 19.67 & 33.00 & 15.59 & 111.38 & 52.04 \\
Coeff. var. & 0.52 & 1.01 & 0.39 & 0.45 & 1.09 & 0.50 \\
Max. & 102 & 82 & 174 & 84 & 608 & 211 \\
min. & 20 & 6 & 30 & 14 & 30 & 17 \\
$\mathbf{N}^{\circ}$. val. & 26 & 16 & 39 & 29 & 24 & 14 \\
\hline
\end{tabular}

Nonetheless, the minimum values are not very different for all three beds, testifying to the high filtration capability of the planting layer (sand + soil), and also of the drainage layer in all cases. It may be postulated, without any formal proof, that the abundance of the reeds' roots and rhizomes acts on the structure and stability of the sludge stock.
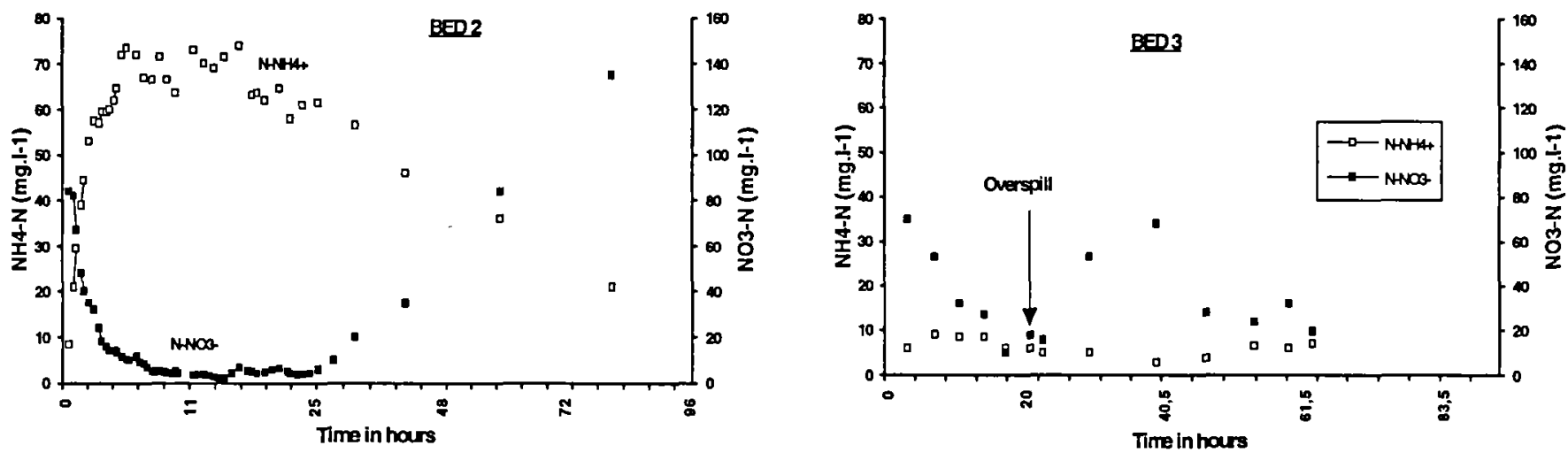

Figure 3 : Concentration changes in ammonium and nitrate salts in the percolation flow of bed 2 and bed 3 in May 1992.

For bed 2, the respective nitrogen concentrations from ammonium and nitrates in the percolation flow (figure 3) are inversely proportional. The 1st flows, appearing 5 or 6 minutes after the feed starts, have very high nitrate loads $(>80 \mathrm{mg} / \mathrm{l})$. 
These are the result of ammonium ions that are absorbed in various places : a) on the biofilm fixed in the drainage layer aggregates , b) in the planting layer (soil + sand), c) in the first few centimetres of sludge, at the interface with the planting layer, in which aerobic mineralization of the sludge has progressively turned it to humus. Nitrification occurs during the drying phase between 2 influent feeds.

After backwashing of this nitrate stock, ammonium salts make up most of the discharged nitrogen substances. Nitrates are again seen to be present when drying rates drop back down sufficiently low (around $5 \mathrm{~mm} \cdot \mathrm{h}^{-1}$ ) whilst ammonium ions disappear.

Since the redox potentials (ORP) in the sludge are incompatible with any internal nitrification, it follows that the latter may only occur in the well aerated drainage layer when the detention time is sufficiently long at the end of the drying process. The same changes were also observed by Nielsen (1990).

On the unplanted bed, the same phenomenon of nitrate backwashing can be observed to begin with. The major difference lies in the low dissolved ammonium salt concentrations in the percolation flows and in the persistence of a high degree of average nitrification, explained by slow drying, again backing up the previously postulated hypothesis of nitrification occurring in the drainage layer.

The measured bicarbonate levels and conductivities also confirm the higher levels of microbiological activity in the planted beds than in the unplanted control bed. The dissolved nitrogen fluxes per unit surface area, for identical drying rates, are 4 to 5 times greater for bed 2 than for bed 3, this being additional proof of a "rhizosphere effect", probably stimulating the density and the activity of micro-organisms responsible for the mineralization process (Hofmann, 1990).

\section{Extracted sludge quality}

The average concentrations, calculated from all the samples taken from the three beds, only differ slightly. As opposed to this, the differences between the minimum values, and especially the maximum values, are significantly greater, particularly for bed 3. Even visually, the sludge from the unplanted bed was not uniform, and therefore why a greater number of samples were taken from it.

It should be remembered that bed 3 was covered with an approximately $8 \mathrm{~cm}$ thick sludge layer containing many fine plant roots, that were unable to be completely removed from the sludge that was analysed. This layer had a lumpy appearance both looking and smelling like excellent top-soil. Two samples were taken from it which had higher dry matter or Total Solids (TS) contents (17.8 et $15.9 \%$ ), than those from other parts of the bed in which the average content was $9.9 \%$. As opposed to this, the nitrogen and phosphorous contents, expressed as a \% of TS (Total Solids) are not very different.

TABLE 4 : THE QUALITY OF SLUDGE EXTRACTED FROM THE 3 BEDS IN DECEMBER 1992

\begin{tabular}{c|cccc|cccc|cccc}
\hline & \multicolumn{4}{|c|}{ BED 1 } & \multicolumn{4}{c|}{ BED 2 } & \multicolumn{4}{c}{ BED 3 } \\
& TS & VS & NK-N & PT-P & TS & VS & NK-N & PT-P & TS & VS & NK-N & PT-P \\
Average & $\mathbf{1 0 . 6}$ & $\mathbf{5 8 . 7}$ & $\mathbf{4 . 4}$ & $\mathbf{1 . 2}$ & $\mathbf{1 1 . 4}$ & $\mathbf{6 1 . 0}$ & $\mathbf{4 . 9}$ & $\mathbf{1 . 3}$ & $\mathbf{1 1 . 0}$ & $\mathbf{6 1 . 6}$ & $\mathbf{5 . 6}$ & $\mathbf{1 . 5}$ \\
Std. dev. & 2.13 & 4.15 & 0.36 & 0.06 & 1.42 & 2.96 & 0.41 & 0.09 & 3.03 & 3.70 & 0.72 & 0.16 \\
Coeff.var. & 0.20 & 0.07 & 0.08 & 0.05 & 0.12 & 0.05 & 0.08 & 0.07 & $\mathbf{0 . 2 8}$ & 0.06 & 0.13 & 0.11 \\
Max. & 13.9 & 61.7 & 4.8 & 1.33 & 14.7 & 64.6 & 5.5 & 1.4 & 17.8 & 65.9 & 7.1 & 1.7 \\
min. & 8.8 & 51.5 & 3.9 & 1.15 & 9.7 & 56.4 & 4.3 & 1.1 & 8.3 & 54.7 & 4.5 & 1.1 \\
$N^{\circ}$.val. & \multicolumn{3}{|c|}{5} & \multicolumn{4}{|c|}{10} & & \multicolumn{4}{c}{13} \\
\hline
\end{tabular}

TS expressed as \%, other parameters in \% of TS, VS = Volatile Solids or Organic Matter

Bed 2, whose sludge stock reached $79 \mathrm{~cm}$, is the bed having the highest TS content and having the lowest differences across all the considered parameters. A representative sample taken from a $10 \mathrm{~cm}$ perimeter around the beds, logically shows the highest TS content $(14.7 \%)$.

Using the average TSS contents measured in the percolation flows, we can estimate that losses in these terms do not exceed $1.2 \%$ of the influent sludge dry matter, characterising excellent retention (or capture) which is unequalled by any other mechanical dewatering system. On bed 3 , the same calculation reveals a sludge loss in the percolation flow of $3.6 \%$. 
The TS content of bed 1 is slightly lower than that of bed 2. Nonetheless, we can consider this value to be excellent considering that the sludge from this bed has had $36 \mathrm{~m}^{3}$ of liquid passed through it in the form of influent flows $\left(28 \mathrm{~m}^{3}\right)$ and recycling of percolation flow $\left(8 \mathrm{~m}^{3}\right)$ in the 4 days preceding desludging.

The dry matter content of sludge from bed 2 is compatible with being transported and spread using a solid muck spreader. In view of the fact that desludging should normally be performed in the summer, the TS contents shown here can be considered as minimum values.

\section{DISCUSSION - CONCLUSION}

The thick growth of reeds creates a large drying network for the sludge's interstitial water along the stems, rhizomes and roots. This water passes through the drainage layer made of gravel, which provides a good compromise between planting medium support capability and permeability.

Since the drainage layer rests on a well ventilated, perforated floor, the oxygen in the air diffuses through the spaces within this granular medium that is colonised by roots and an abundant and particularly nitrifying biomass. The presence of oxygen at this level is fundamental to enabling the reeds to grow abundantly in an organic medium that could rapidly become fermenting, anaerobic and toxic. The rest periods between two feed periods probably contribute to the system's reliability : the risk of biological clogging, related to an over-abundance of biomass fixed on the gravel, is probably limited by the deterioration of reserve substance and predation effects. A deficiency situation is created when flows, loaded in mineral salts coming from the sludge stock, are low.

Sludge stored on reed planted beds is subjected to high levels of mineralization. Indeed, this plays a part in helping to limit the increase in level. Although the observed redox potentials are always low, but nonetheless indicative of a non-septic medium ( $\mathrm{rH} \cong 18$ ), this mineralization does not generate any unpleasant odours.

The sludge, extracted using a mechanical digger with a double bucket, is mixed with the reeds. It has a dryness of approximately $11 \%$ and may be spread on agricultural land using a solid muck spreader. In order to avoid the propagation of the reeds, it is advisable to take a few precautions that may be drawn from experience. The fertiliser value of this sludge is comparable with that of sludge dewatered by other devices for small communities and they contain no additives (polyelectrolytes or lime).

In terms of organic matter (TSS, COD), the percolation flows are generally a lot less loaded than filtrates from other mechanical dewatering systems. In terms of nutrients $(\mathrm{N}, \mathrm{P})$, concentrations of dissolved salts are of the same order, and even better than those from conventional dewatering plants (if we include overflows from the silo and (or) sludge thickener). The backflows to the treatment plant account for $10 \%$ of the nitrogen loads treated by the plant and 5 to $6 \%$ of phosphorous loads. Furthermore, it is not currently possible to predict the compatibility of reed planted drying beds with sludge from sewage treatment plants equipped with coagulant addition facilities, when the consent standard requires this.

During the 24 hours following influent feeds, discharged nitrogenated substances mainly consist of ammonium salts. As opposed to this, towards the end of drying, when percolation flows are low, they contain a high proportion of nitrates that are formed whilst passing through the drainage layer. It would perhaps be possible to spread influent flows throughout the feed days to limit the discharge of ammonium and to increase the nitrate concentrations.

The percolation flows are not septic. After passing through the granular and well aerated drainage layer, their redox potential remains above $300 \mathrm{mV} / \mathrm{NHE}$. They cannot trigger or activate sludge bulking in the plant. Maintaining good oxidising conditions throughout the sludge, that is densely colonised by vegetal matter, guarantees that the percolation flow has negligible impact with respect to the risk of malfunctions related to the biological sludge quality (Duchène, 1993). 
Malfunctions observed in sewage treatment plants are often related to bad sludge management. As demonstrated above, the possibility of direct feeding from the oxidation ditch, after homogenisation, guarantees extraction of a precise and easily adaptable quantity of sludge. The operation may be automated by using timers to control pumps dedicated to this task.

Regular attendance of a plant operator is not necessary during extractions, which should be carried out at suitably spaced intervals whilst the aerating device is operating. Subject to having suitable safety mechanisms, the operator's work is limited to sporadic monitoring and to changing valves to alternately feed the various beds.

Sludge extraction is on a one-off basis, when the beds are periodically desludged, at intervals that have yet to be accurately determined. This interval should be at least every 2 or 3 years, but could be significantly greater if the bed walls were high enough, leaving a minimum free height of 1.5 meters.

However, the current state of knowledge does not allow us to determine the maximum heights beyond which the reeds would be unable to survive.

The increase in sludge level, and thus the desludging frequency depend simultaneously on the influent flow dose, on drying and on the degree of mineralization occurring which itself is influenced by meteorological conditions and especially the temperature. Hofmann (1990) recommended an annual dose of 20 to $30 \mathrm{~kg}$ TSS. $\mathrm{m}^{-2} \cdot \mathrm{an}^{-1}$ for extended aeration sludge. These tests show that it is possible to considerably increase the influent sludge doses (of the order of $55 \mathrm{~kg}$ of TSS. $\mathrm{m}^{-2} \cdot \mathrm{an}^{-1}$ ). Nonetheless, the system is adaptable to all types of situation according to whether we prefer high influent sludge loads or, on the contrary, very infrequent desludging operations.

\section{ACKNOWLEDGEMENTS}

This study would not have been possible without the material and financial participation of the SAUR that now commercialises the process under the name "RHIZOPHYTE ${ }^{\circledR}$ ". They constructed the experimental beds and covered most of the monitoring expenses within the framework of a contract covering several years with the CEMAGREF-LYON. We would also like to thank the Bourg Argental town council for having allowed these tests to take place at their community sewage treatment plant.

\section{REFERENCES}

Boutin, C. (1987). Domestic Wastewater treatment in tanks planted with rooted macrophytes : case study, description of the system, design criteria and efficiency. Wat. Sci. Tech. Vol. 19, $\mathrm{N}^{\circ} 10$, pp 29-40.

Duchène, Ph. (1993). Biological foams : The cause-effect relationship, tests results and combat strategy. In : Proceedings of the First International Specialized Conference on "Microorganisms in Activated Sludge and Biofilm Processes". CFRP-AGHTM (Eds), pp 231-244.

Hofmann, K. (1990). Use of Phragmites in sewage sludge treatment. In : Constructed Wetlands in Water Pollution Control . P.F. Cooper and B.C. Findlater (Eds). Pergamon Press, pp 269-277.

Liénard, A., Boutin, C., Esser, D. (1990). Domestic wastewater treatment with Emergent Hydrophyte beds in France. In : Constructed Wetlands in Water Pollution Control . P.F. Cooper and B.C. Findlater (Eds). Pergamon Press, pp 183-192.

Liénard, A., Esser, D., Deguin, A., Virloget, F. (1990). Sludge dewatering and drying in reed beds : An interesting solution ? General investigations and first trials in France. In : Constructed Wetlands in Water Pollution Control . P.F. Cooper and B.C. Findlater (Eds). Pergamon Press, pp 257-267.

Nielsen, S.M. (1990). Sludge dewatering and mineralization in reed bed systems. In : Constructed Wetlands in Water Pollution Control . P.F. Cooper and B.C. Findlater (Eds). Pergamon Press, pp 245-255. 